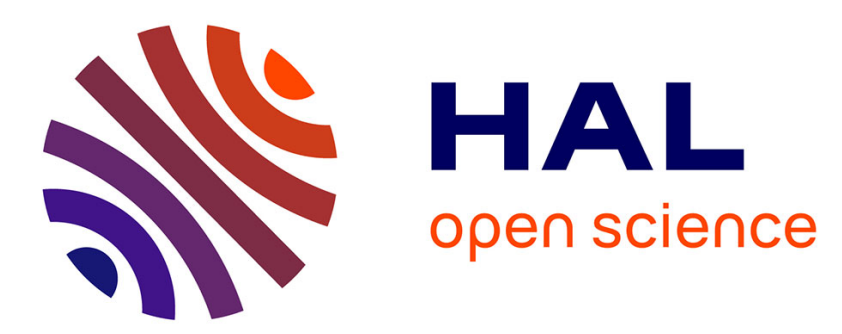

\title{
Microwave induced time-resolved infrared radiometry for subsurface defect detection and characterization
}

\author{
R. Osiander, J. Spicer, J. Murphy
}

\section{To cite this version:}

R. Osiander, J. Spicer, J. Murphy. Microwave induced time-resolved infrared radiometry for subsurface defect detection and characterization. Journal de Physique IV Proceedings, 1994, 04 (C7), pp.C7-563C7-566. 10.1051/jp4:19947132 . jpa-00253187

\section{HAL Id: jpa-00253187 https://hal.science/jpa-00253187}

Submitted on 1 Jan 1994

HAL is a multi-disciplinary open access archive for the deposit and dissemination of scientific research documents, whether they are published or not. The documents may come from teaching and research institutions in France or abroad, or from public or private research centers.
L'archive ouverte pluridisciplinaire HAL, est destinée au dépôt et à la diffusion de documents scientifiques de niveau recherche, publiés ou non, émanant des établissements d'enseignement et de recherche français ou étrangers, des laboratoires publics ou privés. 


\title{
Microwave induced time-resolved infrared radiometry for subsurface defect detection and characterization
}

\author{
R. Osiander, J.W.M. Spicer and J.C. Murphy
}

The Johns Hopkins University, Applied Physics Laboratory, Laurel, MD, 20723-6099, U.S.A.

\begin{abstract}
The use of microwaves as a heating source in time-resolved infrared radiometry provides the ability to heat surface and subsurface microwave-absorbing regions of a specimen directly. This can improve the contrast and spatial resolution of such regions and enhance their detectability when compared with conventional laser or flash lamp sources. Applications such as subsurface water detection or the detection of carbon fiber contaminates in epoxy composites are investigated experimentally and analytically.
\end{abstract}

Due to recent technical developments in the speed, detector array size, and sensitivity of infrared cameras, time resolved infrared radiometry has become an important NDE tool which allows fast area inspection at high spatial resolution. While much prior work has focused on the detection of structural defects or disbonds in a variety of materials, the increasing importance of composite materials requires new approaches to inspection which allow characterization of local material properties. Defects in such materials may have little thermal contrast compared to the matrix material and may be invisible using conventional TRIR methods. However, where the embedding material is a weak microwave absorber, localized microwave absorbing regions can be detected easily. There are three different classes of absorption processes: (1) dielectric loss (e.g. water), (2) magnetic loss, and (3) Joule heating (e.g. electromagnetic radiation interaction with conducting fibers). Examples of Processes 1 and 3 are presented in this paper.

All experiments use an HP $6890 \mathrm{~B}$ Oscillator $(5-10 \mathrm{GHz})$ to produce microwaves at a frequency of 9 GHz. This signal is amplified to a maximum power of $2.3 \mathrm{~W}$ by a Hughes $1277 \mathrm{X}$-band traveling wave tube amplifier and fed into a single flare horn antenna through rectangular wave guide. The antenna has a beam width of about $50 \mathrm{deg}$. and is placed about $15 \mathrm{~cm}$ from the sample. Both the angle of incidence and the polarization of the microwave field relative to the sample are controlled. A $128 \times 128 \mathrm{InSb}$ focal plane array (Santa Barbara Focalplane) operating in the $3-5 \mu \mathrm{m}$ band is used for detection of the IR radiation. The camera has a temperature resolution of about $3 \mathrm{mK}$ and a frame rate as fast as $305 \mathrm{~Hz}$ or $3.3 \mathrm{~ms}$ per frame. The frame synchronization pulse of the infrared camera triggers the microwave oscillator and the sample temperature is monitored as a function of time during the microwave pulse. This allows longer observation times with low power input and hence small temperature rises, as in time resolved infrared radiometry with optical heating $[1,2]$.

The first example focuses on dielectric heating of regions of subsurface water. Water-based defects include blisters in fiberglass or composite structures, or under coatings and paints as a source of corrosion. One example which is shown in Fig. 1a is a disbonded epoxy coating on a steel pipe. Infrared radiometry with optical heating is not very successful with these kinds of defects since the thermal effusivity of water is well matched to the steel and hence shows little thermal contrast in a surface temperature image. In the microwave regime, water has a broad strong absorption band associated with a maximum in the dielectric relaxation near $18 \mathrm{GHz}$ and there is strong absorption at $9 \mathrm{GHz}$. Fig. $1 \mathrm{~b}$ shows an infrared image of the epoxy-coated steel pipe heated with a $15 \mathrm{~s}$ microwave pulse when the disbond is filled with water. The image outlines the disbonded region with no heating of bonded regions showing high contrast at the water defect as compared to optical (surface) heating where the whole sample would be heated. 

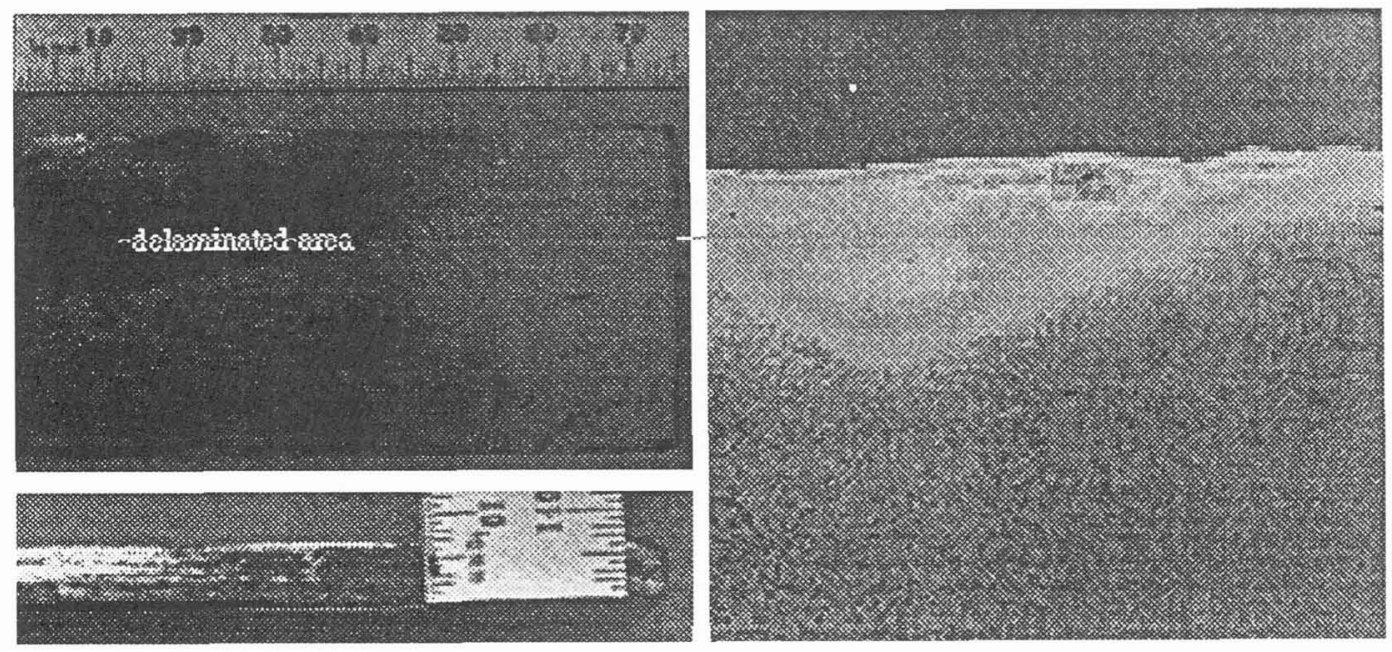

Figure 1a (left): Disbonded epoxy coating on a steel pipe.

Figure $1 \mathrm{~b}$ (right): Infrared image of the water filled disbond after a $15 \mathrm{~s}$ microwave pulse.

The time-dependence of the surface temperature can provide information about the subsurface region. A second sample shown in the insert in Fig. 2 is made from Plexiglass with voids filled with water placed at different depths below the surface using Teflon spacers. The time dependence of the relative surface temperature of points is plotted in Fig. 2 for each thickness. For a 3-layer system with thermal diffusivities $\alpha_{i}$, thermal conductivities $\kappa_{i}$ and layer thicknesses $d$ and $L$ and with an absorption coefficient $\beta$ in the second layer, the surface temperature vs. time during and after a microwave pulse of duration $t_{0}$ (one-dimensional heating) is:

$$
\begin{aligned}
& T(0, t)=\frac{\sqrt{\alpha_{0} \alpha_{1}}}{\kappa_{1}}(1+\Gamma) \sum_{n=0}^{\infty}(-\Gamma)^{n}\left[\left(G\left(\sqrt{\frac{\alpha_{1}}{\alpha_{0}}} \beta .(2 n+1) d, t\right)-e^{-\beta L} G\left(\sqrt{\frac{\alpha_{1}}{\alpha_{0}}} \beta,(2 n+1) d+L \sqrt{\frac{\alpha_{1}}{\alpha_{0}}}, t\right)\right)-\right. \\
& \left.-\vartheta\left(t-t_{0}\right)\left(G\left(\sqrt{\frac{\alpha_{1}}{\alpha_{0}}} \beta,(2 n+1) \alpha, s_{0}\right)-e^{-\beta L} G\left(\sqrt{\frac{\alpha_{1}}{\alpha_{0}}} \beta,(2 n+1) d+L \sqrt{\frac{\alpha_{1}}{\alpha_{0}}}, t_{0}\right)\right)\right] \\
& G(h, x, t)=H_{0} h \int_{0}^{t} e^{-h x+h^{2} \alpha_{0} t} e r f c\left\{\frac{x}{2 \sqrt{\alpha_{0} t}}+h \sqrt{\alpha_{0} t}\right\} d \tau \text {. }
\end{aligned}
$$

In contrast to surface heating, there is a signal even for the case when the reflection coefficient $\Gamma$ vanishes. The thick solid lines in Fig. 2 are calculated using equation 1 and the thermal properties for water, Teflon, and plexiglass. The agreement between experiment and calculations can be considered excellent. Several other materials with dielectric or with magnetic loss have been investigated using the focalplane array camera and analyzed using Eq. 1.

Microwave absorption can also occur in metals, semiconductors and other electrical conductors due to the presence of free electrons. This absorption causes Joule heating which can be monitored with the infrared camera and can for example be used to monitor microwave field distributions [3,4]. The example chosen here is small diameter graphite fibers embedded in a dielectric medium. The fibers are those found in current graphite-epoxy composites. Other examples have also been studied. The detection of graphite fibers in fiberglass composites is shown in the infrared image in Fig. 3a. The image was taken 8 sec after the microwave pulse was applied. The fiber, about $10 \mathrm{~mm}$ long, $0.5 \mathrm{~mm}$ wide and $0.2 \mathrm{~mm}$ thick was purposely embedded inside a fiberglass laminate before curing. The IR-image shows the fiber with high contrast and without any background heating of the matrix. Figure $3 \mathrm{~b}$ shows the time-dependence of the surface temperature for a single point on the fiber. Figure 4 shows the temperature profile across the fiber for different times. This includes regions in the matrix which are heated by diffusion from the fiber and allows the local thermal properties of the matrix to be determined. The temperature rise for a continuous line source as a function of position on the surface is given by [5]:

$$
T(x, t)=\frac{H_{o}}{4 \pi \alpha} \int_{r^{2}}^{\infty} \frac{e^{-u} d u}{u}=-\frac{H_{o}}{4 \pi \alpha} E i\left(-\frac{r^{2}}{4 \alpha t}\right)
$$




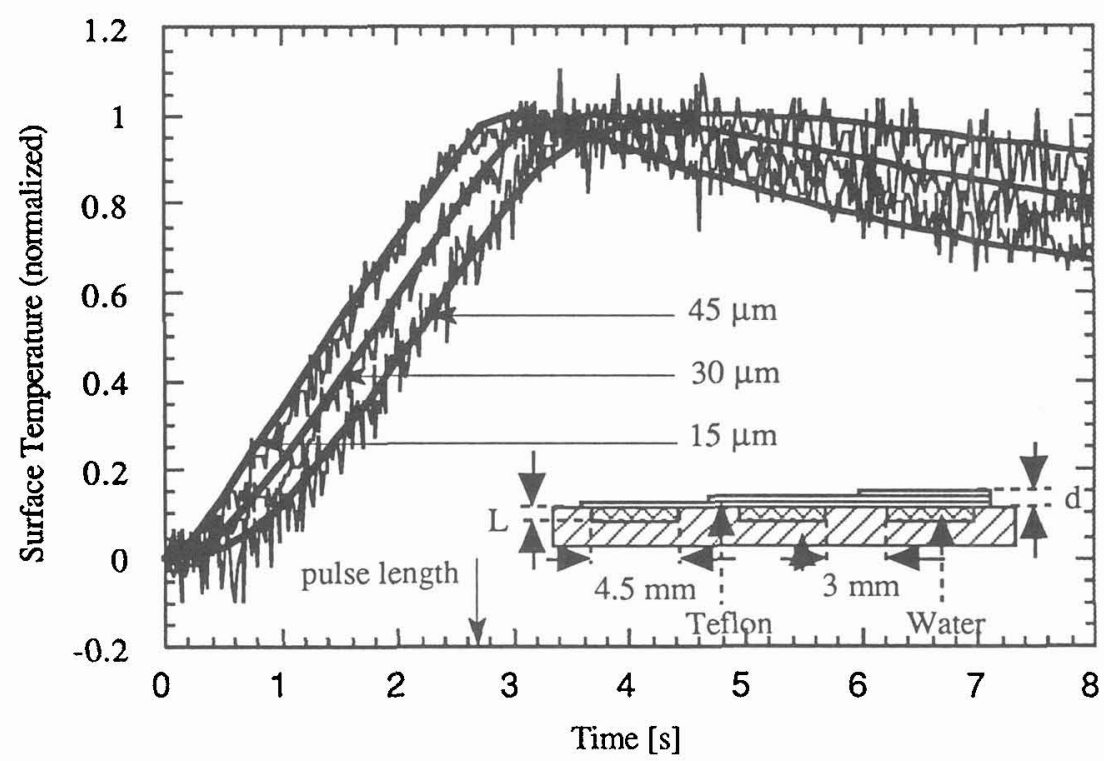

Figure 2: Relative surface temperature rises with microwave pulse heating as a function of time for different Teflon layer thicknesses in the sample shown in the insert.

where $\operatorname{Ei}(x)$ is the exponential integral, $\alpha$ is the thermal diffusivity and $\mathrm{d}$ is the depth of the fiber. The solid lines in figures $3 \mathrm{~b}$ and 4 are calculated with this expression and fitted to the data, yielding a thermal diffusivity of $\alpha=0.003 \mathrm{~cm}^{2} / \mathrm{s}$. The deviations for short times in Fig. 1 might be a result of the infrared transparency of fiberglasss. Further tests have shown that the fiberglass-epoxy is slightly transparent in the 3-5 $\mu \mathrm{m}$ wavelength range and hence the IR signal should be an integral over emission depth below the surface.

An important feature of these measurements is that the spatial resolution is determined by the infrared wavelength and not the microwave wavelength and fibers of only a few microns diameter can be detected. This raises the prospect of a class of embedded, addressable sensors for a range of applications. An example is detection of structural defects in fiber composites especially fiber breakage due to impact damage. Since microwave absorption is larger at fiber breaks than for intact fibers, broken fibers are visible in the IR image under microwave heating.

\section{REFERENCES}

[1] J.W. Maclachlan Spicer, W.D. Kerns, L.C. Aamodt and J.C. Murphy, J. Nondestruc. Eval. 8 (2) (1989) 107.

[2] L.C. Aamodt, J.W. Maclachlan Spicer and J.C. Murphy, J. Appl. Phys. 68 (12) (1990) 6087 .

[3] M.R. Seiler, J.L. Haselwood, and L.A. Stockum, Thermosense XIV, edited by J.K. Eklund, Proc. SPIE 1682, pp. 296-307 (1992).

[4] D.L. Balageas, P. Levesque, and A. Déom, Thermosense XV, edited by J.K. Eklund, Proc. SPIE 1933, pp. 274-285 (1992).

[5] H.S. Carslaw and J.C. Jaeger, Conduction of Heat in Solids (Oxford Univ. Press, London 1959) 

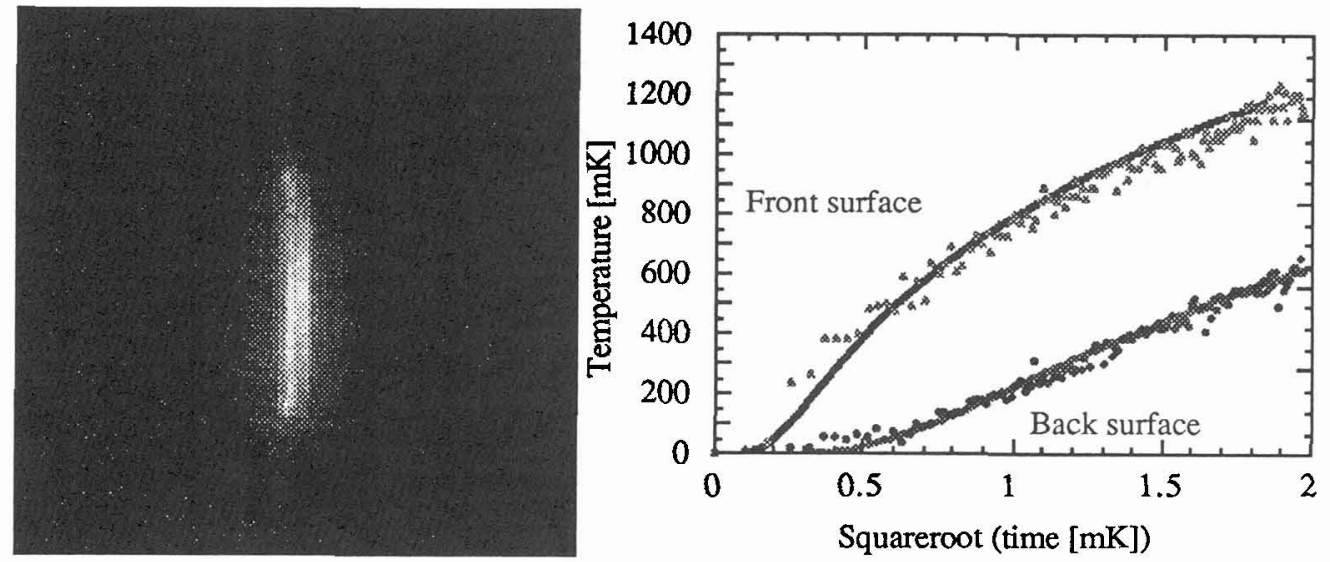

Figure 3a (left): Infrared image of fiberglass-epoxy composite with carbon fiber contaminate after a $8 \mathrm{~s}$ microwave pulse.

Figure $3 \mathrm{~b}$ (right): Surface temperature as a function of square root time for a single point on fibers measured on front and back surface. Solid lines are calculated with equ. (2).

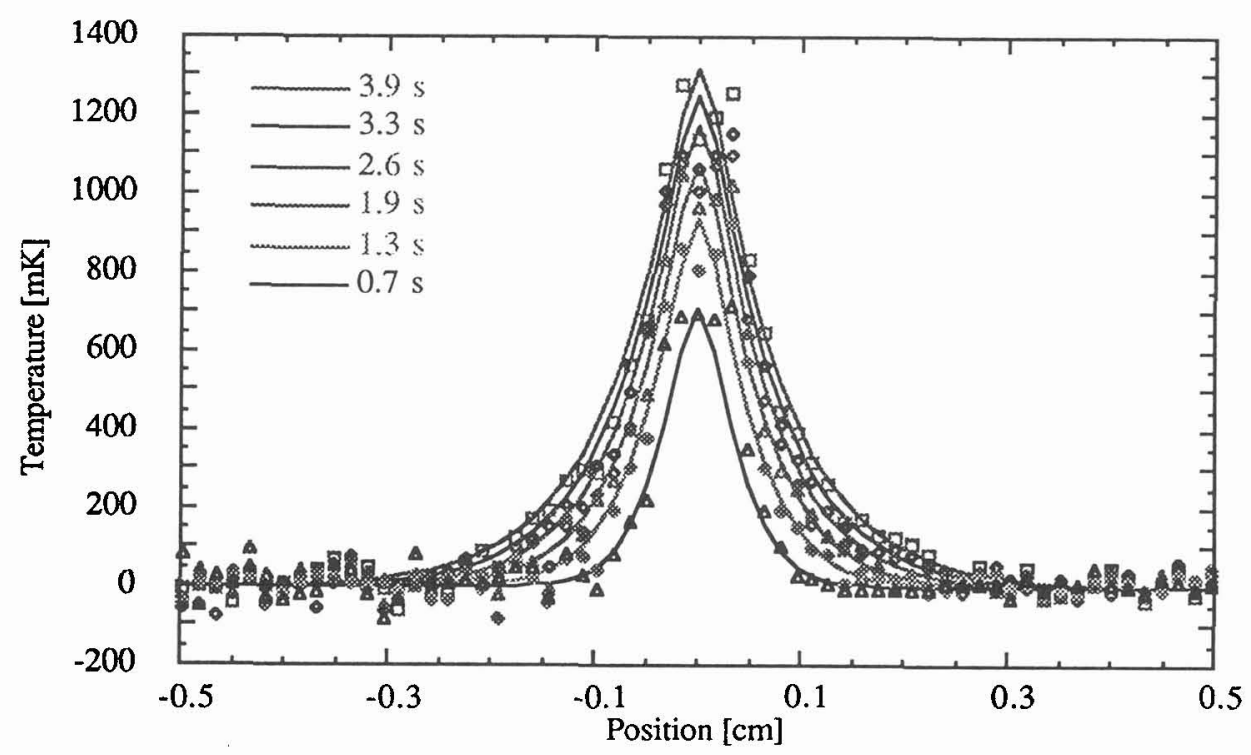

Figure 4: Temperature profile across a carbon fiber in the fiberglass epoxy sample of Fig. 3a at different times during the microwave pulse. Solid lines are calculated with Eq. (2). 